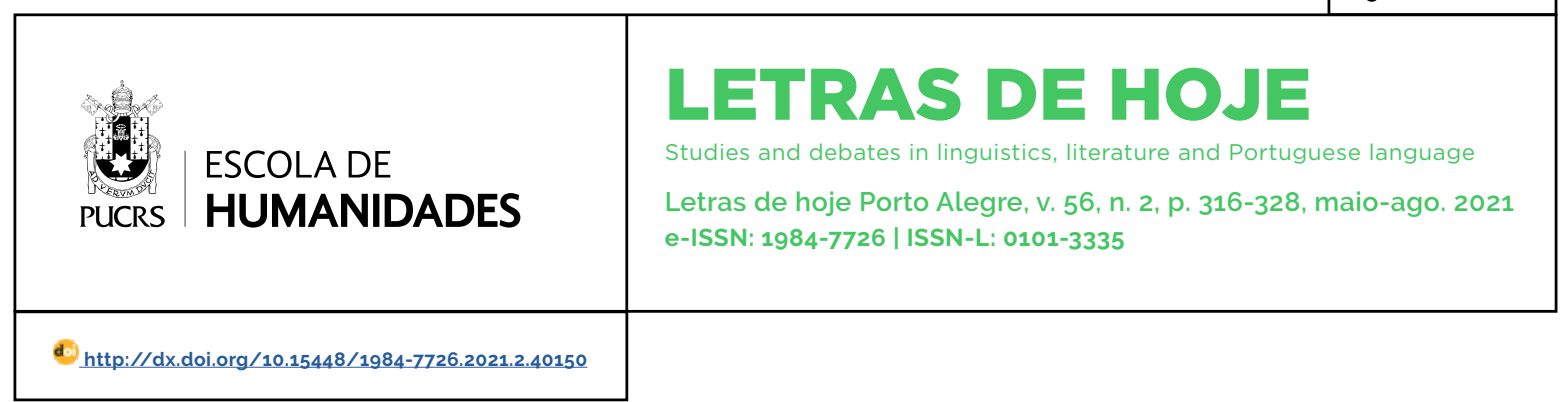

SEÇÃO: O CONTO BRASILEIRO CONTEMPORÂNEO DE AUTORIA FEMININA

\title{
Feminidad disidente, maternidad no normativa y familias nocivas en "La camisa del marido" de Nélida Piñón
}

\author{
Dissident femininity, non-normative motherhood and harmful families in "The husband's \\ shirt" by Nélida Piñón
}

Feminilidade dissidente, maternidade não normativa e familias prejudiciais em "A camisa do marido" de Nélida Piñón

\section{Richard Leonardo- Loayza $^{1}$ orcid.org/0000-0001-6867-2127 rleonardol@unmsm.edu.pe}

Recebido em: 15 fev. 2021 Aprovado em: 3 ago. 2021. Publicado em: 9 nov. 2021

\section{(c) (1)}

Artigo está licenciado sob forma de uma licença Creative Commons Atribuição 4.0 Internacional.
Resumen: Este artículo estudia "La camisa del marido", de Nélida Piñón. Se desea demostrar que en este texto se ofrece una representación suigéneris de la mujer, la cual ya no es más vista como un ser en minusvalia social (débil, pasivo, dependiente), sino que se presenta como alguien que posee agencia, es decir, que es capaz de problematizar su circunstancia y, además, hace algo para poder superarla. Asimismo, se desea probar que, en este cuento, se representa a la "mala madre", entendida como el personaje femenino que no está dispuesto a seguir los mandatos sociales que la maternidad impone. Esta "mala madre" privilegia su condición individual antes que la referida a sus hijos. Finalmente, también se quiere demostrar que "La camisa del marido" es un cuento en el que se problematiza lo difícil de las relaciones familiares, las que no aseguran ni el afecto ni la armonia entre las personas que conforman una familia.

Palabras clave: Nélida Piñón. "La camisa del marido". Feminidad disidente. Maternidad no normativa. Familias nocivas.

Abstract: This article analyzes "The husband's shirt", by Nélida Piñón. It is intended to demonstrate that this text offers a suigéneris representation of women, which is no longer seen as a socially handicapped (weak, passive, dependet), but is presented as someone who has agency, that is, that he is capable of problematizing his circumstance and, furthermore, he does something to overcome it. Likewise, we want to prove that, in this story, the "bad mother" is represented, understood as the female character who is not willing to follow the social mandates that motherhood imposes. This "bad mother" privileges her individual condition rather than that referred to her children. Finally, it also wants to show that "The husband's shirt" is a story in which the difficulty of family relationships is problematized, those that do not ensure affection or harmony between the people who make up a family. Keywords: Nélida Piñón. "The husband's shirt". Dissident femininity. Non-normative maternity. Harmful families.

Resumo: Este artigo estuda "A camisa do marido", de Nélida Piñón. Pretende-se demonstrar que este texto oferece uma representação sui generis da mulher, que não é mais vista como deficiente social (fraca, passiva, dependente), mas se apresenta como alguém que tem agência, ou seja, que é capaz de problematizar sua circunstância e, além disso, faz algo para poder superá-la. Da mesma forma, queremos comprovar que, nesta história, está representada a "mãe má", entendida como a personagem feminina que não se dispõe a seguir os mandatos sociais que a maternidade impõe. Essa "mãe má" privilegia sua condição individual, em vez da de seus filhos. Por fim, quer também mostrar que "A camisa do marido" é uma história em que se problematiza a dificuldade das relações familiares, aquelas que não garantem afeto ou harmonia entre as pessoas que compõem uma familia. Palavras-chave: Nélida Piñón. "A camisa do marido". Feminilidade dissidente. Maternidade não normativa. Famílias prejudiciais. 


\section{Introducción}

Nélida Piñón es una de las voces más interesantes de la literatura brasileña contemporánea. Además, puede decirse que es una de las escritoras en lengua portuguesa que está más cerca de lberoamérica, ya sea por sus orígenes (tiene ascendencia gallega) o por una cuestión de afectos (continuamente realiza viajes a España e Hispanoamérica, en los que visita amigos y familiares).

Piñón es una autora que destaca por la escritura de sus novelas; sin embargo, el cuento no le es esquivo, género en el que ha logrado elaborar una serie de piezas de alto nivel dignos de la antología más rigurosa. Entre sus libros de cuentos se tiene Tempos das frutas (1966), Sala de armas (1973), O calor das coisas (1980), Cortejo do divino e outros contos escolhidos (2001) y $A$ camisa do marido (2014). ${ }^{2}$

En este último volumen la escritora brasileña explora la complejidad del mundo familiar. Se trata de nueve cuentos en los que se muestra sin ningún tipo de idealización ni tapujo a la familia, la cual no necesariamente está conformada por individuos que se profesan algún tipo de afecto positivo. A pesar de esta situación, por alguna razón extraña, no pueden desligarse de su núcleo familiar. Es que Piñón tiene la cualidad de construir un mundo "en el que predominan la tensión interior y la ambivalencia de los protagonistas junto a la fluidez de la realidad externa" (TRIAS FOLCH, 2010, p. 324).

Uno de los cuentos más representativos de este libro es el que le da título al volumen: "La camisa del marido". Este artículo estudia el relato mencionado y desea demostrar que, en dicho texto, se ofrece una representación suigéneris de la mujer, la cual ya no es más vista como un ser en minusvalia social (débil, pasivo, dependiente), sino que se presenta como alguien que posee agencia, es decir, que es capaz de problematizar su circunstancia y, además, hacer algo para poder superarla. Asimismo, se desea probar que en este cuento de Nélida Piñón se representa a la "mala madre", o madre no normativa, entendida como el personaje femenino que no sigue los mandatos sociales que la maternidad occidental impone (Leonardo-Loayza, 2020, p. 156). Esta "mala madre" privilegia su condición individual antes que la referida a sus hijos. Finalmente, también se quiere demostrar que "La camisa del marido" es un cuento en el que se problematiza lo dificil de las relaciones familiares, las que no aseguran ni el afecto ni la armonía entre las personas que conforman esta familia.

\section{"La camisa del marido": una familia nociva y una venganza}

"La camisa del marido" es la historia de una familia compuesta por Elisa y Pedro, una pareja de esposos, que tienen tres hijos: Tiago, Lucas y Mateus. A diferencia de una familia tradicional, en la que se espera que se manifieste el amor y el sacrificio de los padres en salvaguarda de los hijos, en esta no hay lugar para dichos sentimientos, más bien lo que se presenta es un abandono continuo hacia estos últimos, aparejado de agresiones y humillaciones sistemáticas, lo que ha derivado en un rencor de los hijos a sus padres. Un día, aparece muerto Pedro. Tal situación agudiza las diferencias que existian entre la madre y los hijos, asimismo, emergen los resentimientos entre los hermanos, los cuales se disputan el control de la familia. Elisa, quien estaba muy unida a su esposo, jura encontrar al culpable de la muerte de este, mientras tanto les hace saber a sus hijos que en ausencia de Pedro, ella es quien seguirá teniendo el poder en la casa. Todo parecía entrar es una especie de normalidad, cuando una mañana encuentran a Elisa muerta al lado de un hombre que ha sido acuchillado. Al inicio no se sabe qué sucedió, pero Mateus, quien presenció oculto la escena del crimen, les cuenta a sus hermanos que un hombre extraño llegó a la casa paterna. Minutos después, otro desconocido ingresó a la casa sin que el primero lo notara. Mateus, entonces, vio como el segundo hombre mató a cuchilladas a

\footnotetext{
2 Para el análisis del texto se empleará la versión en castellano publicada por la Editorial Alfaguara, el 2015. Todas las citas del cuento corresponden a dicha edición.
} 
este último. En eso, apareció Elisa, habló con el homicida, le quitó el cuchillo y, diciendo algo al cielo, tomó unas pastillas que tenía guardadas en el bolsillo. El asesino huyó, mientras Mateus se acercaba para ayudar a su madre. De esta manera, la familia se entera de que Elisa había contratado a un sicario para vengar a Pedro, pero luego de logrado este hecho decide envenenarse, porque, al parecer, no podía soportar vivir sin su esposo.

\section{Feminidad disidente: mujeres voraces y con coraje}

A lo largo del tiempo son los hombres los que han colonizado la representación de las mujeres, son ellos los que se han arrogado el derecho de hablar por y sobre ellas. Como dice Frances Borzello: "las imágenes de la mujer han estado tradicionalmente en propiedad del hombre" (1998, p. 57). De este modo, los varones han empleado una serie de estereotipos encaminados a suturar la identidad de las mujeres, las cuales han sido definidas en términos que puedan permitir su control y dominación.

La imagen que ofrece "La camisa del marido" sobre las mujeres es contrahegemónica. El personaje principal, Elisa, no está representada desde los atributos que el sistema heteropatriarcal utiliza para describir a las mujeres, es decir, no se trata de un individuo pasivo, débil, en minusvalía social, sino que es alguien con una peculiar personalidad. En el texto se lee:

Muchas veces, el rostro de la matriarca expresaba lo contrario de lo que decía. Era habitual que, de pronto, después de un breve instante de serenidad, se echara a gritar, arrojándose a la yugular de algún animal con un puñal afilado para sacrificarlo sin piedad, sin que su difunto esposo pudiera hacer nada por detenerla. Y estaría asimismo dispuesta a ejecutar a cualquiera de cuya inocencia dudara (PIÑÓN, 2015, p. 11-12).

Una característica propia de este personaje es la inestabilidad emocional, su ambivalencia (que podría reiterar otro estereotipo que se usa para referirse a las mujeres: la volubilidad), pero lo interesante es que también desarrolla una conducta activa, violenta, en la que no cabe la piedad. Elisa es una mujer con rasgos que socialmente se les endilga a los varones. Resulta importante señalar que este personaje tiene cierta autonomía, porque el esposo en ocasiones, como la que refiere el fragmento citado, no "puede hacer nada para detenerla".

En esta misma línea de sentido, resulta significativo que Elisa desarrolle una sexualidad plena. A diferencia de la representación de la mujer tradicional, que es mostrada como no proclive al sexo (sobre todo, si se trata de una mujer casada, la cual es perfilada desde el decoro), Elisa es alguien que lo practica vigorosamente, disfrutando al límite de cada encuentro con su marido. Así, este último expresa:

\begin{abstract}
Esa mujer me ama con desvarío. Preferiría que me amara menos. Me sentiria a salvo de sus embestidas; no me deja en paz. La intensidad es asesina, no tiene mesura. Siempre supe que Elisa era feroz, y es y la amo, pues su amor me beneficia. Pero mi amor es insuficiente. Porque ella quiere más, exige que sea solo suyo. Mi carne es suya porque la suya es mía. Todo en ella obliga al cuerpo a seguir el camino del crimen pasional (PIÑÓN, 2015, p. 12-13).
\end{abstract}

Elisa es una persona que "ama con desvario". Este enunciado puede entenderse como que ella no solo gusta de la sexualidad, sino que llega a extremos irracionales por practicarla. Tanto es así que Pedro confiesa que preferiría que su pareja lo amara menos, es decir, que le exija sexualmente menos. Esta manera de vivir la sexualidad de parte de la mujer pone en riesgo la masculinidad de Pedro, porque la pone a prueba y la cuestiona constantemente. Por esta razón, el recelo y la repulsa a dicha actitud. Asimismo, debe recordarse, junto a Foucault (2015), que la familia tiene como una de sus funciones el controlar la sexualidad de la mujer, la que es considerada como "un cuerpo integralmente saturado de sexualidad" (FOUCAULT, 2015, p. 126), pero que el caso de Elisa esta se ha desatado furiosamente al punto de que esposo afirma que "su amor es insuficiente" (léase capacidad para copular). Como se aprecia en el fragmento citado, Pedro se siente amenazado, no está en paz, porque esta sexualidad es "intensa", "no tiene mesura".

Ahora, en la cita que se ha realizado del cuento no es gratuito que se mencione la carne, como un sinónimo del cuerpo. El cuerpo es visto como 
algo trascendental, sagrado, posicionado en la esfera del pensamiento; en cambio, la carne, es más terrenal, relaciona lo humano con lo animal. Alenka Zupančič con razón explica: "La humanidad, en su nivel más fundamental, es una desviación de la Naturaleza, y notablemente del Animal" (2013, p. 79). La unión entre Pedro y Elisa se basa en una relación carnal, no se habla sobre sentimientos, sino sobre carnalidad, la misma que permite el contacto de los cuerpos, el intercambio de los sexos: "Mi carne es suya porque la suya es mía", dice Pedro. Ambos esposos están ligados por el sexo. Más adelante, Pedro cuenta: "En una ocasión, por pedir tregua a mi cuerpo agotado, ella protestó, sospechó que otra mujer me había saciado. Tuve que sofocar sus gritos con la almohada para que no la oyeran nuestros hijos" (PIÑóN, 2015, p. 13). Elisa es una mujer insaciable sexualmente, que deja exhausto el cuerpo de su pareja. Ella no puede creer que Pedro, su cuerpo, no esté a la altura de su deseo, por eso desconfía, piensa que su marido se satisfizo con otra mujer. Elisa es una mujer sexualizada, en la que prima la carne, el único medio para alcanzar la satisfacción. Ella es carne, por eso los celos, los gritos de reclamo en el lecho sin que le importe que sus hijos puedan escucharla o no.

Ahora, si bien ante los ojos de Pedro, Elisa manifiesta un comportamiento sexual descontrolado, también podría leerse dicha conducta como un gesto de descolonización del cuerpo y el deseo de la mujer respecto al hombre. Como añade Nuria Varela: "la sexualidad de las mujeres ha sido arrebatada históricamente por los varones" (2019, p. 343). Son estos los que desde siempre se han apropiado de la sexualidad de las mujeres, han procurado controlarla, limitarla. En este contexto, la decisión de Elisa de vivir su sexualidad en pleno implica un acto de independencia, de recuperación del cuerpo y su deseo.

De otra parte, Elisa es un personaje fuerte, decidido, quien no se deja doblegar por cualquier situación adversa. Así lo considera el narrador:

Buscaba estar a solas con el fantasma de Pedro. Su silencio intimidaba a los familiares, a quienes les costaba creer que el disgusto de haber perdido a su esposo la hubiera debilita- do, y le hubiese arrebatado su instinto de lucha. Quienes conocian a la madre, habiendo sido la imagen del padre, apostaban a que no tardaria en recuperar el gobierno de la casa, acaso con ánimo de venganza (PIÑóN, 2015, p. 16).

Los que la conocian no se habian equivocado. Elisa se recupera de la pérdida de su esposo, nuevamente toma las riendas de su casa y buscará vengar al esposo. Como se aprecia, esta mujer posee "instinto de lucha", tenacidad, fortaleza. Resulta interesante la valoración que le da el narrador, quien la compara con su marido. Se sugiere que tanto Pedro como Elisa son dos personajes similares (ella es "la imagen del padre") En ese sentido, esta mujer es masculinizada, por tener los mismos atributos que su esposo Pedro. La masculinización no tiene como fundamento los rasgos físicos de Elisa, sino su temperamento, lo que le permite, incluso, imponerse a otros hombres de mayor tamaño. El narrador comenta: "La altura de la madre contrastaba con la de los hijos, todos ellos altos como el padre. Pero era capaz de enfrentarse a hombres y animales pese a ser pequeña. No temía a sus hijos, a los que gobernaba con simples gestos" (PIÑÓN, 2015, p. 17). Elisa es pequeña, pero pese a esta peculiaridad consigue hacerse obedecer con los hijos, los cuales son altos y, por supuesto, más fuertes. La madre logra controlarlos con la mirada, con los gestos. Se trata de una mujer con un carácter fuerte, supuestamente semejante al de un varón. Por eso, este narrador no duda en decir que "era capaz de enfrentarse a hombres y animales".

Elisa desarrolla una feminidad disidente, pues su representación escapa a los estereotipos con los cuales el sistema heteropatriarcal, desde siempre, ha descrito a la mujer, convirtiéndola en objeto y, restándole, por lo tanto, la dignidad de sujeto. Elisa no solo es igual al hombre, sino que incluso es más fuerte, lo que se manifiesta en el carácter, sino también en el ejercicio de una sexualidad acorde a sus necesidades. Esta representación sobre la mujer es importante, porque permite visualizar otro tipo de mujer más allá de la típica descripción que el sistema heteropatriarcal ha realizado sobre ella. De este modo, "La camisa del marido" de Nelida Piñón ofrece una alternativa 
en el régimen de visión de los géneros, posibilita pensar a la mujer en otros términos.

\section{Las "malas madres" o la maternidad no normativa}

Las mujeres cuando llegan a procrear tienen que seguir una serie de prescripciones si desean ser reconocidas socialmente como madres. Cada época, cada cultura, establece los modos de ejecutar la maternidad y el rol materno, es decir, qué es lo que se espera y valora como lo correcto o lo incorrecto en el ejercicio de ser madres. Históricamente los atributos vinculados a la condición de maternidad la caracterizan por ser una actividad natural, esencial e instintiva de las mujeres. Esta concepción se reproduce en la esfera de lo privado y de lo doméstico, resaltando las capacidades femeninas en cuanto a la reproducción y a los cuidados. De este modo, la división sexual del trabajo establece que las mujeres además de la concepción, la gestación, el parto y la lactancia, deben ocuparse en forma exclusiva de la crianza de los hijos, porque poseen "una especie de caja de herramientas innata que induce a las mujeres más que a los hombres a criar a sus hijos, ya sean biológicos o adoptados, y a cuidar de ellos" (DONATH, 2017, p. 59). Desde esta lógica de la cultura patriarcal y el androcentrismo, se establece la idea de que ser madres es el destino natural de las mujeres, aunque subrepticiamente perpetúe situaciones de desigualdad social, política y económica entre ellas y los hombres. Cristina Palomar (2004) lo resume en los siguientes términos:

El proceso de construcción social de la maternidad supone la generación de una serie de mandatos relativos al ejercicio de la maternidad encarnados en los sujetos y en las instituciones, y reproducidos por los discursos, las imágenes y las representaciones que producen de esta manera, un complejo imaginario maternal basado en una idea esencialista respecto a la práctica de la maternidad (2004, p. 16).

El ser madre acarrea un conjunto de estereotipos que se manifiestan como una representación ideal y abstracta, que encarna la esencia atribuida a la maternidad. De esta manera, la madre es portadora "del amor sin limites" (RECALCATI, 2018, p. 130) y el "instinto materno" (BADINTER, 1980, p. 12), del que se derivan virtudes como la paciencia, el cuidado, la tolerancia, la protección, el sacrificio y la entrega desinteresada de las mujeres a la maternidad. Del cumplimiento o no de estos mandatos se producen dos estereotipos: las buenas y las malas madres. Respecto a las buenas madres, Ricardo Garay (2008) explica que estos estereotipos

no se reducen a esta prescripción sino que las
normas incluyen además una serie de prohi-
biciones en torno a los defectos a eliminar: el
egoismo, el erotismo, la hostilidad y el no dejar
transparentar sus ansiedades, necesidades y
deseos [...]. El ideal maternal abarca no solo
los comportamientos a tener, sino también los
sentimientos que se deben vivenciar. El ideal
maternal es la interiorización de todos estos
preceptos y prescripciones que normativizan
la experiencia de la maternidad (2008, p. 32).

El comportamiento de las madres no solo está supeditado a las acciones por realizar en beneficio de sus hijos, sino del control de los afectos y sentimientos que les prodigan. Como puede apreciarse, estos mandatos también regulan el mundo emocional de las madres, reglamentando aquello que es o no lo apropiado. Aunque, como dice Orna Donath (2017), no hay "una única emoción que los hijos inspiren" (2017, p. 63), el imaginario social asume y espera que todas las mujeres sientan lo mismo si desean ser vistas como "buenas madres". Se exige que estas se sacrifiquen por los hijos, los cuiden, y que, además, los quieran a todos sin objeción ni condición alguna. Un aspecto importante para tener en cuenta es que estas regulaciones sociales, plasmadas en el imaginario colectivo, no solo se producen de parte de la sociedad, representada en el resto de la gente, sino que están interiorizadas en las propias madres. Por una parte, como indica Julia Kristeva, porque en la abnegación y el sacrificio materno, algunas mujeres encuentran gratificación y gozo (1987, p. 219). Por otra, en la esperanza de que se cumplan las promesas que, desde siempre, le ha formulado el sistema patriarcal. Donath lo explica así: 
La maternidad la conducirá la la mujer] a una existencia valiosa y justificada, un estado que corrobora su necesidad y vitalidad. La maternidad anunciará tanto al mundo como asi misma su extensión de mujer en toda la extensión de la palabra, una figura moral que no solo paga su deuda con la naturaleza al crear vida, sino que además la protege y la promueve (2017, p. 34).

Es oportuno preguntarse si todas las mujeres están dispuestas a llegar a ser "buenas madres" o, si todas ellas poseen las condiciones materiales y emocionales para lograr tal ideal. Lo cierto es que existe una gran cantidad de mujeres que no quiere, o no puede, lidiar con estas exigencias, ya que son dificiles y, muchas veces, imposibles de alcanzar. En este contexto es que aparece la figura de la "mala madre". Palomar (2004) define esta categoría como:

el resultado del contraste que se establece con el ideal de género fabricado culturalmente para crear el mito de la mujer-madre, basado en la creencia en el instinto materno, en el amor materno y en el sacrificio y la entrega gustosa de las mujeres a la maternidad. Visto así, las "malas madres" son aquellas mujeres que no cumplen con los ideales de la maternidad socialmente construida con base en tres campos fundamentales: el legal, el moral y el de la salud. Las "buenas madres", por contraste, son aquellas que se ajustan a dichos ideales (2004, p. 19).

Las "malas madres" siempre han estado presentes en la historia de la humanidad, pero recién, desde un tiempo a esta parte, este personaje social ha sido materia de escritura. Sobre todo, en la literatura latinoamericana y, en especial, en la obra de las escritoras como Valeria Luiselli, Ariana Harwicz, Gabriela Wiener, Pilar Quintana, Brenda Navarro o Guadalupe Nettel, por citar a algunas de las más representativas. Las mencionadas autoras han intentado comprender las circunstancias de la aparición de este personaje social, asi como evidenciar la complejidad que implica asumir la maternidad y tratar de ejercerla. Como explica Jacqueline Rose, el ser madre conlleva: "una gama amplia y compleja de emociones que queda silenciada o suprimida, y que borra de golpe todo aquello que un ser humano siente por dentro" (2018, p. 100).

"La camisa del marido" es un relato que ofrece una representación de la madre que colisiona con la imagen clásica que se tiene de ella como un ser abnegado, sufrido, que es capaz de dejar todo por sus hijos. Por ejemplo, Elisa tiene una percepción especial sobre la relación entre padres e hijos:

Ella misma sirvió los platos que solian gustarle a su marido, a condición de que evocaran a su padre en las comidas, pues al muerto debian su hartura. Y con un gesto impreciso, les mostraba que la fortuna reunida entre los dos quedaria bajo su custodia.

Durante aquellas semanas hizo diversas advertencias con escasas palabras, si bien dejando claro que su esposo, Pedro, nombre de apóstol. habia sido sacrificado para salvarlos. - Ha muerto por vosotros. En su esfuerzo por traer comida a casa, vuestro padre se creó enemigos. Nunca quiso una familia pobre (PIÑÓN. 2015, p.13-14).

Para esta mujer, la relación entre padres e hijos tiene un fundamento en la deuda que los segundos contraen con los primeros. Los padres se sacrifican por los hijos, lo que estos últimos siempre deberian tener presente. En esta especie de ética, los hijos deben tener en claro que lo que los padres logran reunir en la vida es para el disfrute de ellos y no de los hijos, los cuales solo podrán acceder a todos estos bienes una vez que los padres hayan muerto. Los hijos no ignoran este pensamiento. Por ejemplo, Tiago, el hijo mayor dice:

\begin{abstract}
Sufro por ser el primogénito. Siento que cargo con el peso del mundo. Aguanto más de lo que puedo el dramatismo de mamá, que se cobra de sus hijos la sangre que gotea entre sus dedos. Es irascible y autoritaria, y no deja de repetir que la vida es injusta y el destino, amargo. Ahora teníamos la despensa abarrotada, pero papá ya no estaba entre nosotros para mojar el pan en la salsa de la carne asada, como solia gustarle. Aludia a la pobreza como si nuestra casa no fuera la más rica de la vecindad. Y lo hacia para que evocáramos a papá y la deuda que habiamos contraído con él (PIÑÓN, 2015, p. 14-15).
\end{abstract}

El final de la cita refiere la deuda que tienen los hijos con el padre. Es precisamente la madre la que se encarga de recordarles esta situación. Tiago considera a su madre como irascible. autoritaria, exageradamente dramática, alguien que busca echarles en cara a sus hijos lo que han hecho sus padres para mantenerlos. Tiago no se equivoca, Elisa es realmente agresiva con 
él y el resto de sus hermanos. En un pasaje del cuento, Tiago relata:

\begin{abstract}
No he oído bien lo que me ha dicho mamá al regresar a su habitación. Me cuesta oírla, salvo cuando sube la voz y me ofende. Cuando hace eso, emplea un tono cruel. No me lo perdona ni el día de mi cumpleaños, cuando me da el dinero: - No te olvides de que me debes la vida (PIÑÓN, 2015, p. 21).
\end{abstract}

La madre le grita, lo ofende, es cruel con su primogénito. Ni siquiera el día del cumpleaños de este hijo, Elisa deja de recordarle que ellos, los hijos, tienen una deuda con sus padres, pero ahora obsérvese que no se trata solo de la manutención, sino de la vida misma. Es como si ella sugiriese que haberlo traído al mundo es un hecho que debe ser retribuido, pagado de alguna manera.

Elisa no es una buena madre, por el contrario, se trata de un personaje que no itera ninguno de los comportamientos que supuestamente se atribuyen a la mujer cuando ejerce la maternidad. Tiago declara:

Apenas si soy capaz de descifrar lo que me dice mi madre. Aun así, he intentado reconciliarme con ella después de la muerte de mi padre. Quizá me escuchará, me acariciará, me ayudará a olvidar las veces que he deseado su muerte. Pero es esquiva. Solo se deja ver al final de la tarde, cuando llegan mis hermanos, todos a la vez, como si así lo hubiéramos acordado. Acepta nuestra presencia sin una triste muestra de cariño. Manda servir la comida, los dulces y el café. No hay ni un ápice de amor en ella, salvo para mi padre, que permanece vivo en su memoria. Al contrario: busca la brecha por donde atacar a cada uno de sus hijos. Para ella somos aves de rapiña que solo queremos dinero. Antes de haber podido abrir la boca, nos dijo que solo heredaremos a su muerte. Se comporta según la voluntad de su marido, pues ambos firmaron tal acuerdo en el infierno del paraiso en el que vivieron durante treinta años. Siempre quisieron expulsar a esos hijos que les arrebataban la soledad que les exigia el amor que sentían el uno por el otro (PIÑÓN, 2015, p. 14-15).

El fragmento es sumamente interesante, porque revela una serie de cuestiones claves en la historia que en el cuento se narra. La primera, como consecuencia del maltrato de la madre, los hijos también la odian, incluso desean su muerte. Elisa es esquiva, desconsiderada, sin ningún signo de amor por sus hijos. Según testimonio de Tiago, esta mujer busca la menor oportunidad para atacarlos. Resulta significativo que los vea como aves de rapiña, aparentemente deseosos del dinero. Esta podría ser la razón de su animadversión hacia los hijos, pero el último enunciado de este fragmento revela otra cosa. Los hijos no fueron queridos, porque, de alguna manera, "les arrebataban la soledad que les exigía el amor que sentían el uno por el otro". Lo que significa que los hijos fueron vistos como un obstáculo que no permitía que el amor entre Pedro y Elisa se desarrollará a plenitud. Esto último muestra como esta madre, lejos de asumir los mandatos de la maternidad y dejar todo por los hijos, no lo hace, porque siente que es más importante su relación conyugal. Debe recordarse que esta relación está basada fundamentalmente en el sexo, no en los sentimientos. Esta es una de las razones por las que se puede decir que Elisa es la manifestación de lo que se conoce como "mala madre" o madre no normativa, porque trasgrede aquello que se espera del ejercicio de la maternidad tradicional, es decir, el cuidado, la protección y, por añadidura, el amor y el respeto.

Elisa tiene un pésimo concepto de sus hijos. Ninguno de los tres les parece lo suficientemente competentes. El narrador, en un pasaje del cuento, explica: "a su juicio, sus hijos fallaban siempre que les encargaba una tarea" (PIÑóN, 2015, p. 16). Los considera como individuos torpes, incapaces de hacer bien aquello que se les solicita. Así lo declara la propia Elisa:

No sé ni por qué le pido al primogénito que me haga compañía. Si este hijo mío no sirve para nada. Nació cobarde. Y no puedo confiar en Mateus y Lucas. Son de corazón indulgente. No conocen las leyes de la guerra. No heredaron mi temperamento, y tampoco el de su padre. a causa del cual nos temiamos incluso entre nosotros. Con los años aprendimos que uno era un peligro para el otro. Y esta certidumbre beneficiaba la vida conyugal, mantenía la cama caliente (PIÑÓN, 2015, p. 17).

El psicoanálisis freudiano enseña que el hijo siempre representa para la madre un sustituto del falo simbólico que a ella le falta (FREUD, 1992, p. 186). El hijo de esta manera está destinado a resarcir a su madre de la falta. Pero Lacan 
(2008), quien sigue en esto a Freud, asume que este sustituto nunca satisface realmente a la madre; su deseo del falo aún persiste después de tener el hijo. Y más adelante, el propio Lacan dice: "El Deseo de la madre no es algo que pueda soportarse tal cual, que pueda resultarles indiferente. Siempre produce estragos. Estar en la boca de un cocodrilo, eso es la Madre" (2015, p. 118). Como se observa, en "La camisa del marido", Elisa considera que sus hijos no sirven para nada. Mientras el mayor es un cobarde, los dos menores tienen el corazón indulgente (lo perdonan todo). Estas características en su prole los hace despreciarlos. Elisa reconoce que sus hijos no heredaron ni el carácter suyo ni el de su esposo, un carácter explosivo y peligroso para ambos. Con justa razón, Joan Copjec, siguiendo en esto a Lacan señala: "el Uno del amor no funde a los enamorados - sujeto y objeto; amante y amado, de cualquier sexo; hombre y mujer - en uno, sino que se expone su disyunción" (2006, p. 101). A pesar del amor que se tienen Elisa y Pedro, se dan cuenta de sus diferencias. Esta especie de lucha que entablaban ambos esposos beneficiaba la vida conyugal. Nuevamente aparece la idea de que el amor no se traduce solo en sentimientos, sino, sobre todo, en el sexo ("la cama caliente").

Precisamente esta actividad le dará consistencia a su relación de pareja y, a la par, termina alejando a los hijos de ellos, los cuales se sentirán excluidos, expulsados simbólicamente ante el amor voraz que se profesaban sus padres. Incluso, en la muerte, estos hijos son rechazados por Elisa. Detallando su posible deceso, esta madre le dice a su primogénito lo siguiente:

- La lápida de vuestro padre es provisional. Ha llegado el momento de preparar un sepulcro que nos acoja a los dos y a nadie más de la familia. Cuando se trata de estos asuntos, la sangre no sirve para la eternidad (PIÑÓN, 2015, p. 17).

Elisa no concibe compartir un sepulcro familiar, sino solo reservado para la pareja. De esta manera, aún en la muerte los hijos son echados, marginados de esta relación, en la que "la sangre no sirve para la eternidad". Se reitera la idea de que el amor conyugal está por encima del amor filial, el cual pareciera estar solo supeditado, en el mejor de los casos, a lo terrenal. Elisa comenta:

\begin{abstract}
He exigido a mis hijos que dispongan un túmulo espacioso, donde quepan nuestras dos historias, una misma que comenzó cuando nos enamoramos. Y que quede espacio para los sentimientos que experimentamos a lo largo del tiempo. Pero ¿tendrán suficiente sensibilidad para comprender la tragedia de un amor que no termina ni después de la muerte? (PIÑÓN, 2015, p. 17-18).
\end{abstract}

Para la protagonista del relato, el amor que compartía con su esposo es algo que ni siquiera la muerte puede derrotar, debido a que incluso después de producida esta seguirá perdurando, realizándose eternamente.

Ahora, no solo Tiago tiene una opinión negativa sobre el comportamiento de su madre, sino también el hermano intermedio, Lucas, quien tampoco ama a su madre y experimenta un gran resentimiento por su padre:

Soy el único de los hijos que no habla, que no responde, que vive recogido en el vacio de la propia existencia. Poco importa que mamá me quiera o no, o que papá se olvidara de mí, de su hijo mediano, cuyo nombre, Lucas, escogió con cierto desdén. Nunca me llevaba a pescar Me dejaba atrás y se iba con Tiago y Mateus. Mis hermanos se sentian héroes, capaces de traer a casa la ballena de Jonás y el cadáver de papá, a quien nunca quisieron. Era un padre para quien sus hijos no existian. Solo tenía ojos para mamá y para las monedas que iba apilando sobre la cómoda del dormitorio antes de darles un uso (PIÑóN, 2015, p. 18).

A diferencia de Tiago, a Lucas pareciera no importarle el amor de su madre. Lo que más le duele es el hecho de que su padre no lo haya tomado en cuenta, que haya preferido más tanto al hijo mayor como al último. En opinión de Lucas, Pedro fue un mal padre, porque no se ocupaba de sus hijos, sino que solo "tenía ojos para su mamá y para las monedas que iba apilando en la cómoda". En su casa habia una especie de protocolo: "Había que amar a la esposa y el dinero por encima de todas las cosas. Palabras que mamá aplaudia, a la vez que nos daba la espalda. Ambos excluían el mundo para poseerse, e hicieron de sus hijos unos inválidos" (PIÑÓN, 2015, p. 19). "Amar a la esposa y el dinero por encima de todas las cosas", incluso por 
encima de los hijos. Dicho protocolo tendrá unas consecuencias terribles para los hijos, quienes se convertirán en personas inútiles, sin capacidad de reacción ante los diversos eventos de la vida.

Elisa es la manifestación de "la mala madre" o madre no normativa. No sigue los mandatos que la sociedad impone a las mujeres para reconocerlas como madres. Elisa no ama a sus hijos, por el contrario, los considera un obstáculo para la realización plena de su relación amorosa con Pedro, su marido. Elisa considera que la maternidad es un ejercicio de poder que se basa en una deuda que los hijos contraen con los padres. El haberles dado la vida, mantenerlos durante sus años primeros, es motivo de exigirles a estos hijos que paguen. Entonces, la maternidad deja de ser un acto sublime y desprendido para convertirse en una transacción calculada, que obliga a unos a obedecer a otros.

\section{Familias nocivas o historias de vida que se repiten}

Si bien es una tarea difícil definir lo que es una familia, lo cierto es que, como dice María Elena Benitez Pérez, "en cualquier lugar del mundo se [la] reconoce (...) entre los aspectos más valorados en la vida de los individuos" (2017, p. 61). En efecto, la familia cumple importantes funciones que se relacionan con la preservación de la vida humana, asi como con su desarrollo y bienestar: función biológica, económica, afectiva, educativa, protectora, recreativa (BENITEZ PÉREZ, 2017, p. 62). La familia es considerada como un sostén social, el espacio en el que los individuos se sienten cómodos y seguros.

La familia conformada por Elisa y Pedro, junto a sus hijos Tiago, Lucas y Mateus es una de carácter no convencional, porque no se ajustan a lo que supuestamente se espera que sean las familias. Se trata de una familia nociva. Por ejemplo, el hijo intermedio, Lucas, siente que la influencia de sus padres y hermanos en su vida es funesta.

¿Qué testimonio me deja esta familia, que me persigue siempre que intento soñar? Lei en algún libro que la inquietud del alma asegura la perpetuidad de la civilización. ¿Será cierto? La realidad es que vivo solo, mi casa es pe- queña, y en ella recibo a mujeres con la orden de marcharse después de acostarnos. Apenas si soporto la vida, y mi único consuelo ahora es aguardar la muerte de mamá para librarme de esta familia (PIÑÓN, 2015, p. 9).

La familia es vista como un obstáculo en la existencia de este personaje, una fuerza inicua que boicotea cualquier intento de "soñar", de crear planes a futuro. Por esta razón, es probable que Lucas haya preferido vivir solo, sin compromisos, enredado en amorios de una noche. Un aspecto resaltante es que este personaje intenta librarse de su familia y considera como una salida posible la muerte de su madre.

Esta perspectiva negativa acerca de la familia la comparte Tiago, que siente un profundo rencor por Elisa, su madre, pero también desarrolla una relación conflictiva con sus hermanos, a quienes no soporta. Así, mientras realiza los preparativos para organizar todo lo relativo al sepulcro de sus padres, Tiago dice:

\begin{abstract}
Ella solo ve defectos en todo lo que hago. Es tan difícil agradarla, o poder contar con mis hermanos, que disfrutan cuando fracaso. Mateus me mira con desdén solo porque es el pequeño. Para ellos soy un cordero a punto de ser sacrificado en el tiempo pascual (PIÑÓN, 2015, p. 20-21).
\end{abstract}

Este personaje está convencido que sus hermanos no lo quieren, que incluso disfrutan con su fracaso. Por ejemplo, está seguro de que Mateus, el último hermano, lo mira con desdén, sin ningún tipo de respeto. El símil del cordero es muy significativo, porque Tiago se ve a sí mismo como una víctima, un ser para el sacrificio.

Una cuestión que no deja de llamar la atención es que Tiago se casa con una mujer muy parecida a su madre, en el carácter. Esta mujer también lo maltrata y le hace la vida imposible, porque es incapaz de enfrentar los abusos y desplantes que recibe de Elisa. Por ejemplo, Marta, asi se llama la esposa:

le servia la comida fria para expresar su descontento. Su marido aceptaba que lo recriminara con palabras evasivas, reclamando a Tiago una reacción que no habia modo de activar. Pese a todo, ella le exigia que fuera en busca de su madre en aquel mismo momento y la golpeara y vertiera veneno en su café (PIÑÓN, 2015, p. 22). 
La familia que forman Tiago y Marta también es nociva, porque lejos de ser un espacio de compresión para la satisfacción de ambos, se convierte en un lugar de lucha continua. Marta no está satisfecha con su esposo. Así lo declara:

Soy la mujer de este hombre y me arrepiento. Lamento estar casada con él y pertenecer a su familia. Estoy esperando a que vuelva de casa de su madre. En general, nunca llega tarde, ni renuncia a regresar a este nido destruido, como yo preferiría. No bebe, no fuma y solo me es infiel con putas. Es rápido en esas visitas. Por mi podria quedarse en el burdel para siempre. Pero ¿quién iba a ocupar su lugar y mantenerme? ¿Cómo voy a renunciar a su herencia? Ya ha llegado: acaba de meter la llave en la cerradura. $\mathrm{Ha}$ entrado. Tengo que recibirlo sabiendo de antemano que es un hombre derrotado, que no reacciona (PIÑÓN, 2015, p. 21-22).

En esta nueva familia tampoco están presentes los afectos positivos, como el amor o el interés por el otro, sino que es una puesta en escena repetida de la misma relación que tiene Tiago con su madre, en la que el odio y la agresión están presentes. Un aspecto para destacar del fragmento citado es que cuando Marta expresa que desearía que Tiago no regrese a ese "nido destruido", rápidamente se arrepiente de lo dicho, porque si se marchara el esposo quién la mantendría. Así, puede decirse que lo que une a esta mujer con Tiago es el interés económico, la seguridad que este, mal que bien, le brinda. Precisamente, una de las cosas que más odia Marta de Tiago es que su marido no tiene carácter, para reclamar los bienes que le corresponden como hijo mayor de la familia, y que les daría a los dos una mejor vida:

Marta se percata el estatus que posee su esposo, por eso el reclamo constante:

Marta responde al mutismo de su esposo clavándole las uñas en el brazo, descontenta por estar casada con un cobarde, cuyos padres únicamente le dieron la vida para que los sirviera, sin compensarlo siquiera por el maltrato (PIÑóN, 2015, p. 23).

Marta se percata del tipo de relación que tiene Tiago con sus padres: es una deuda. Por este motivo, dice que los padres de su esposo "únicamente le dieron la vida para que los sirviera", para que les pagara el hecho de haberlo traído al mundo. Tiago no se inmuta ante los reclamos de su esposa; sin embargo, igual que con su madre, tampoco expresa sus sentimientos. Solo se dedica a escuchar. Así, el narrador cuenta:

Su marido era indiferente a las protestas. Y, para paliar sus vulgares amonestaciones, se tapaba los oídos, incapaz de soportar el sufrimiento que madre y esposa le infligian. - Acabaré matando a las dos - murmuró un día, recogido en la iglesia, cerca del altar (PIÑÓN, 2015, p. 23).

Tiago piensa que acabará por matar a las dos mujeres que, como afirma el narrador, le infligen un sufrimiento insoportable. Pero esto es solo una rabieta, porque, de alguna manera, Tiago se ha acostumbrado a vivir en esa atmósfera de violencia y rencor. Por otra parte, Tiago no es ajeno al hecho de que su esposa repita la conducta de su madre, por eso dice:

Esta mujer es igual de cruel que mamá. Van a la par. Solo que Marta ignora que mamá tiene los sentidos de un animal y jamás baja la guardia. Solo se evadía de la realidad con papá. Aun así, recuperaba la atención, censuraba a su marido, contradiciendo cualquier cosa que dijera, a riesgo de perder el único interlocutor que jamás habia tenido (PIÑÓN, 2015, p. 22).

La pregunta que surge es por qué razón alguien se casa con una persona que es igual a su madre, a pesar de que esta mujer es una persona perversa. Habría que entenderlo desde el psicoanálisis, específicamente desde la repetición de las historias personales. Como acota Elina Wechsler: "el sujeto se coloca una y otra vez en la misma posición, pero no la reconoce. A la popular afirmación: 'se trata del destino', Freud responderá con la contundencia 'se trata de la repetición inconsciente' (2001, p. 17). En efecto, el regresar a la misma posición implica no salir de la normalidad, por más escabrosa o negativa que sea. Tener una mujer como Marta, igual a su madre, asegura a Tiago un ambiente que le permite reproducir no solo la relación con esta última, por más conflictiva que esta sea, sino que puede recrear el ambiente paterno, al cual está habituado este personaje.

Un aspecto interesante de esta historia es que Tiago, si bien no puede lidiar ni con su madre ni 
con su esposa desarrolla una actitud peculiar con el resto de las mujeres. Así, el narrador relata:

\begin{abstract}
Tiago devoró el plato frío y se fue a la cama. Ya no contaba con su mujer para satisfacer sus instintos. Su cuerpo ya no despertaba sus deseos. Tal indiferencia se extendía al resto de mujeres, con excepción de aquellas a las que frecuentaba en el burdel del pueblo. Con ellas ponía a prueba la firmeza de su miembro, golpeándolas con el impulso de la rabia que le instilaban madre y esposa, mujeres de una misma raza maldita (PIÑÓN, 2015, p. 23).
\end{abstract}

Con las únicas mujeres que puede relacionarse realmente Tiago es con las que trabajan en la casa de citas. Con ellas, "ponía a prueba la firmeza de su miembro, golpeándolas con el impulso de la rabia que le instilaban madre y esposa, mujeres de una misma raza maldita". Solo con las prostitutas este hombre puede ejercer su masculinidad, la cual pareciera suspendida cada vez que debe enfrentar a su madre o a su esposa, dos versiones de una "misma raza maldita". Como se nota en esta última cita, se reitera la idea que tanto Elisa y Marta son iguales. Además, el hecho de elegir a Marta como pareja no es producto del azar, sino de una cuestión propia del inconsciente de Tiago. Cabe anotar que se puede leer esta decisión como una forma de procurar el goce, tal como los lacanianos lo entienden, es decir, "el placer en el dolor" (ŽIŽEK, 1994, p. 67)3. Tiago solo puede sentirse bien en ese estado nocivo, que los padres, pero en especial la madre, han establecido para él y sus hermanos.

\section{Cuando una camisa es algo más que una camisa}

En "La camisa del marido" se desarrolla una manifestación de fetichismo muy interesante. En este relato se dice que:

Tras el entierro, una vez en el dormitorio, sola por primera vez en treinta años, Elisa se desnudó. El espejo revelaba un cuerpo envejecido. Para tal momento, escogió el camisón de la noche de bodas, que olia a naftalina de tantos años metido en el cajón. Y pensó qué podía hacer con las prendas intimas del marido que este había conservado como recuerdo de aquella noche de amor. Decidió entonces que la camisa que él llevaba puesta el día de su muerte lo sustituiria en el lecho. Para ello, guardó aquella prenda manchada de sangre en una urna, y la dejó sobre la cama, como el recuerdo más perdurable de todos. Tal reliquia demostraba un celo que él habría apreciado (PIÑÓN, 2015, p. 12).

Nótese que, en su primera noche de viuda, Elisa no tiene mejor idea que dormir con la camisa que Pedro llevaba precisamente el día en el que lo mataron. Resulta significativo que esta mujer asuma esta prenda ensangrentada, como un sustituto del marido muerto en el lecho. Por una parte, esta operación metonímica de sustituir al marido por una camisa remite al hecho de que esta mujer necesita tener la presencia de Pedro en su cama. Por otra, esta acción revela una práctica fetichista.

Como se vio líneas atrás, la relación entre ambos esposos fue muy intensa y en la que el cuerpo, lo carnal, desempeñaba un rol fundamental. Ahora que el marido ya no está, Elisa necesita recurrir a una presencia tangible, un objeto, que ocupe el lugar del esposo. De esta manera, elige la camisa que portaba Pedro cuando lo asesinaron. Debe recordarse que desde Kraff-Ebing, en la última década del siglo XIX, se emplea este término para referirse a una conducta sexual, definiendo el fetichismo como una perversión sexual, en la cual la excitación depende de modo absoluto de la presencia de un objeto específico (el fetiche). Asimismo, como dice Dylan Evans, el fetiche "es por lo general un objeto inanimado, por ejemplo un zapato o una prenda interior" (2002, p. 92).

Definitivamente el fetiche tiene una connotación sexual. En este orden de ideas, tiene sentido que Elisa le pida a su hijo Tiago que mande a construir un sepulcro que alberge solo a la pareja. Tiago dice:

No sé si cumplir el encargo que me ha encomendado mamá sin que al menos me dé el trazado de la sepultura que he visto en su poder, porque lo hace para ponerme a prueba y averiguar si seré capaz de adivinar lo que desea. ¿Y por qué insiste en llamar a la sepultura "morada", como si el esqueleto de papá fuera a hacerle el amor? (PIÑÓN, 2015, p. 20).

\footnotetext{
3 Asimismo, puede decirse que el goce es el "excedente" derivado de "nuestro conocimiento de que el placer involucra la excitación de penetrar en un dominio prohibido, de modo que nuestro placer incluye un cierto displacer" (ŽlŽEK, 1998, p. 312).
} 
Elisa llama "morada" a la sepultura, es decir un lugar, donde se habita, donde "se vive". Esto molesta a Tiago, porque relaciona el término que emplea su madre con un lugar en el que sus padres seguirán prolongando su amor ("como si el esqueleto de papá fuera a hacerle el amor"). La molestia del hijo mayor se entiende, porque precisamente esta obsesión sexual que tenía el uno por el otro fue una de las causas del olvido y maltrato que sufrieron los hijos durante toda su vida.

Ahora, no es casual que Elisa llame "morada" al sepulcro y no quiera que este espacio sea compartido por sus hijos en un determinado momento. Lo que sucede es que esta madre piensa, efectivamente, que prolongará su relación con Pedro más allá de la muerte. Por eso dice: "Pedro vive todavía, sin haber resucitado al tercer dia. No ha muerto aún porque mi amor no le deja (PIÑóN, 2015, p. 15). Siguiendo esta lógica, Elisa desea un espacio exclusivo para los dos, lejos de los hijos, en el que puedan su esposo y ella seguir amándose infinitamente.

Al final del relato, esta camisa del padre cambia de valor simbólico. Así, cuando el hermano menor termina su relato sobre lo acaecido con la madre, Tiago.

Miró alrededor, como si se despidiera de los presentes. Les dio la espalda y fue a refugiarse al dormitorio de su madre. Abrió la urna que permanecia sobre la cama, sacó la camisa ensangrentada de su padre y gritó a los que se agrupaban al otro lado de la puerta:

- Me oís bien? La camisa de papá es mía. Con ella revindico mi progenitura (PIÑÓN, 2015, p. 37).

La camisa del padre ha pasado de ser un objeto sexualizado, desde el punto de vista de la madre, a uno que contiene el poder, ahora, desde la perspectiva del hijo. Este objeto legitima la primogenitura de Tiago, la valida ante el resto de los hermanos, en especial ante Mateus, quien de algún modo anhela arrebatarle ese privilegio. De esta manera dice:

- De hoy en adelante, este cuarto en el mío. Nadie entrará en él sin permiso. Las llaves de esta casa son mías, y así será con todas las pertenencias.

El benjamin retrocedió sin abandonar el pasillo. Sus dedos se crisparon como garras, prepa- rándose para un combate sin final previsible. No habría tregua entre ellos.

- Acaba de iniciarse la batalla entre Cain y Abel-sentenció Marta, al verse abandonada por su marido, desde la sala donde yacia el cadáver de Elisa (PIÑÓN, 2015, p. 37-38).

Una vez muerta la madre, los hermanos se disputan el poder en el hogar paterno, lo que equivale a disponer de los bienes materiales y simbólicos de la familia. Por tradición, el primogénito debería poseer ciertos privilegios al interior de este núcleo familiar, pero el menor no se lo va a permitir, porque no solo no ama a su hermano mayor, sino que no lo respeta. Por eso, la esposa de este último sugiere que acaba de iniciarse la batalla entre Caín y Abel, un enfrentamiento fratricida.

\section{Conclusiones}

"La camisa del marido" es un cuento valioso, porque muestra las complejidades a las que se ven enfrentadas las familias. Por un lado, los esposos que se aman tanto, que consideran que sus hijos son estorbos para la realización de dicha relación. Por esta razón, los dejan de lado, agrediéndolos o humillándolos. Asimismo, la relación de los hijos con sus padres, los cuales, al no verse amados, desarrollan un rencor hacia ellos. Pero lo más interesante, es que dicho sentimiento negativo se extrapola a los hermanos, quienes son percibidos entre ellos como competidores desleales.

Asimismo, el relato nos muestra una serie de representaciones no convencionales de las mujeres. Elisa performa una feminidad disidente, porque no encaja en la versión estereotipada con el que el sistema heteropatriarcal sutura la identidad de las mujeres, es decir, no es un ser pasivo, débil, sino que se está ante un personaje fuerte, decidido, que lucha por lograr aquello que desea. Elisa no espera, sino que va detrás de lo que quiere. Un ejemplo, es la satisfacción sexual. Puede decirse que ella asume el rol activo en la relación con su esposo, Pedro. Tanto es así, que este último confiesa que se siente amenazado ante la voracidad de su pareja. 
De otra parte, también el relato presenta la representación de una maternidad no normativa, es decir, aquel ejercicio en el que no se sigue los mandatos sociales que impone la sociedad, para reconocer a una mujer como madre. Elisa no cuida a sus hijos, tampoco los ama o siente consideración por ellos. Busca la manera de ofenderlos y agredirlos constantemente. Se trata de una "mala madre", que privilegia su satisfacción sexual antes que su obligación como madre.

En suma, "La camisa delmarido" aborda la temática de la familia, como un espacio en el que los conflictos existen, pero que usualmente, por la tradición o los convencionalismos, no se hace público. Por eso, este texto es una pieza valiente, descarnadamente sincera, que muestra los antagonismos a los que los seres humanos se enfrentan pese a formar parte de un mismo núcleo familiar.

\section{Referencias}

BADINTER, Elizabeth. ¿Existe el amor maternal? Historia del amor maternal. Siglos XVIII al XX. Barcelona: Paidós, 1980

BENITEZ PÉREZ, María Elena. La familia: desde lo tradicional a lo discutible. Novedades en población, La Habana, n. 26, p. 58-68, 2011. http://scielo.sld.cu/pdf/ rnp/v13n26/rnp050217.pdf

BORZELLO, Frances. La mujer objeto. In: PUPPO, Flavia. (comp.). Mercado de deseos. Una introducción en los géneros del sexo. Buenos Aires: La Marca, 1998.

COPJEC, Joan. Imaginemos que la mujer no existe. Ética y sublimación. Buenos Aires: Fondo de Cultura Económica, 2006.

DONATH, Orna. Madres arrepentidas. Una mirada radical a la maternidad y sus falacias sociales. Barcelona: Resevoir Books, 2017.

EVANS, Dylan. Diccionario introductorio de psicoanálisis lacaniano. Buenos Aires: Paidós, 2005

FOUCAULT, Michel. Historia de la sexualidad. La voluntad del saber. México: Siglo Veintiuno Editores, 2005. t. 1

FREUD, Sigmund. El sepultamiento del complejo de Edipo (1924). In: Obras completas. El yo y el ello y otras obras (1923-1925). Buenos Aires: Amorrortu Editores, 1992. p. $177-187$.

GARAY, Ricardo. El destino de ser madres: la ideología de la maternidad como soporte discursivo de las nuevas tecnologías reproductivas. In: TARDUCCI, Mónica. Maternidades en el siglo XXI. Buenos Aires: Espacio, 2018. p. 29-59.

LACAN, Jacques. El seminario 5. Las formaciones del inconsciente. Buenos Aires: Paidós, 2008.
LACAN, Jacques. El seminario 17. El reverso del psicoanálisis. Buenos Aires: Paidós, 2015

LEONARDO-LOAYZA, RICHARD. Maternidades proscritas, mandatos sociales y violencia en La perra, de Pilar Quintana. Estudios de Literatura Colombiana, Medellín, n. 47, p. 151-168, 2020.

KRISTEVA, Julia. Historias de amor. México: Siglo Veintiuno editores, 1987.

PALOMAR, Cristina. Malas Madres: la construcción social de la maternidad. Debate Feminista, México D.F., n. 30, p. $12-34,2004$

PIÑÓN, Nélida. La camisa del marido. Barcelona: Alfaguara, 2015

RECALCATI, Massimo. Las manos de la madre. Deseo, fantasmas y herencia de lo materno. Barcelona: Anagrama, 2018.

ROSE, Jacqueline. Madres. Un ensayo sobre la crueldad y el amor. Madrid: Siruela, 2018.

VARELA, Nuria. Feminismo 4.O. La cuarta ola. Barcelona: Peguin Random House, 2019.

WECHSLER, Elina. Psicoanálisis en la tragedia. De las tragedias neuróticas al drama universal. Buenos Aires: Biblioteca Nueva, 2001

TRIAS FOLCH, Luisa. Literatura brasileña. Madrid: Síntesis, 2010.

ŽIŽEK, Slavoj. iGoza tu sintoma! Jacques Lacan dentro y fuera de Hollywood. Buenos Aires: Ediciones Nueva visión, 1994

ŽIŽEK, Slavoj. Porque no saben lo que hacen. El goce como factor político. Buenos Aires: Paidós, 1998.

ZUPANČıČ, Alenka. La sexualidad dentro de los limites de la mera razón. Santiago de Chile: Palinodia, 2013.

\section{Richard Leonardo-Loayza}

Doctor en Literatura peruana y Latinoamericana por la Universidad Nacional Mayor de San Marcos (UNMSM), en Lima, Perú; profesor de literatura latinoamericana en esta misma casa de estudios.

\section{Endereço para correspondência}

Richard Leonardo-Loayza

Universidad Nacional Mayor de San Marcos

Facultad de Letras y Ciencias Humanas

Ciudad Universitaria UNMSM

Calle Germán Amézaga, 375 - Lima 1

15081

Lima, Perú

Os textos deste artigo foram conferidos pela Poá Comunicação antes da publicação. 